\title{
Effect of milking stall dimensions on upper limb and shoulder muscle activity in milkers
}

\author{
Marianne Cockburn, ${ }^{1 *}$ Yamenah Gómez, ${ }^{1,2,3}$ Matthias Schick, ${ }^{1,4}$ Nicola A. Maffiuletti, ${ }^{5}$ Lorenz Gygax, ${ }^{6,7}$ \\ Pascal Savary, ${ }^{1,7}$ and Christina Umstätter ${ }^{1}$ \\ ${ }^{1}$ Competitiveness and System Evaluation, Agroscope, Tänikon 1, 8356 Ettenhausen, Switzerland \\ ${ }^{2}$ Ethology and Animal Welfare Unit, Department of Environmental System Sciences, ETH Zürich, 8092 Zürich, Switzerland \\ ${ }^{3}$ Centre for Proper Housing of Poultry and Rabbits (ZTHZ), Division of Animal Welfare Veterinary Public Health Institute, University of Bern, \\ Burgerweg 22, 3052 Zollikofen, Switzerland \\ ${ }^{4}$ Division of Animal Husbandry \& Dairy Production, Strickhof, Eschikon 21, 8315 Lindau, Switzerland \\ ${ }^{5}$ Human Performance Lab, Schulthess Klinik, Lengghalde, 8008 Zürich, Switzerland \\ ${ }^{6}$ Albrecht Daniel Thaer Institute of Agricultural and Horticultural Sciences, Humboldt University Berlin, 10115 Berlin, Germany \\ ${ }^{7}$ Centre for Proper Housing of Ruminants and Pigs, Federal Food Safety and Veterinary Office (FSVO), Agroscope, \\ Institute of Livestock Sciences (ILS), Tänikon, 8356 Ettenhausen, Switzerland
}

\section{ABSTRACT}

Increasing societal awareness for animal welfare can promote changes in legislation. Some of these changes may also affect the person that interacts with the animal in a shared workspace, such as in milking stalls. Swiss milking stalls were designed many years ago, when cows were smaller than they are today. A recent animal-based study indicated that welfare decreased in cows exposed to restricted space allowance in milking stalls, which had resulted from increasing body size without adjustment of milking stall dimensions. However, changing the milking stall dimensions without considering the milker may be detrimental. For many years, health issues, particularly of the upper limb and shoulders, have affected milking personnel. The current study investigated the effect of large and standard milking stall dimensions on muscle activity in milkers (as a measure of workload) during milking. This assessment is fundamental to ensure that legislation improving animal welfare does not jeopardize human health. The study took place in an experimental milking parlor that allowed for size adjustment of the individual milking stall. Nine milkers performed 2 shifts of milking in a herringbone and 2 shifts in a side-by-side milking parlor. The milking stall dimensions were large on one side and standard on the other side of the parlor; the 2 sides were switched between milking shifts. We used surface electromyography to monitor bilateral muscle activity of forearm (flexor carpi ulnaris), arm (biceps brachii), and shoulder (deltoideus anterior; upper trapezius) muscles. Statistical analysis was performed

Received July 2, 2018.

Accepted January 26, 2019.

*Corresponding author: marianne.cockburn@agroscope.admin.ch separately for the herringbone and the side-by-side parlor for each muscle using mean and maximum muscle activity as the target variables in a linear mixed-effects model. The analysis showed that the different milking stall dimensions did not consistently affect activity of the measured muscles. Our results suggest that milking stall dimensions are not a primary risk factor for poor ergonomics in parlor workers.

Key words: ergonomics, surface electromyography, herringbone parlor, side-by-side parlor

\section{INTRODUCTION}

Heavy loads and repetitive and static movements during milking have been affecting the health of milkers. Milkers are prone to carpal tunnel syndrome and pronator syndrome (Stål et al., 1998). As an example, Patil et al. (2012) reported that $16.6 \%$ of milkers developed carpal tunnel syndrome compared with $3.6 \%$ of nonparlor workers, which may have been caused by repetitive static movements and vibration of soft tissues. When attaching the cluster, the milker holds the milking unit in one hand and uses the other hand to attach the teat cups to the teats. The cluster weighs between 2.0 and $3.5 \mathrm{~kg}$ and, in most European countries, is held in a static posture in the palm of the hand with the fingers extended (Stål et al., 1998).

Recently, cow welfare has been taken into consideration for milking parlor design. The dimension of the individual cow standing area (milking stall) for milking parlors in Switzerland has not been adjusted in the past 20 yr. During that time, dairy cows exhibited a genetic trend for increasing size as a result of breeding for a higher milk yield (Hansen, 2000). Schönmuth and Löber (2006) reported an increase in sacral height in Holstein-Friesian heifers by $0.12 \mathrm{~m}$, from 1.37 to 
$1.49 \mathrm{~m}$, between 1980 and 1996. Recent evidence suggests that milking stall size and design are important for an animal-friendly milking environment (Gómez et al., 2017). A larger space allowance may increase cow welfare, as it could enable the cow to stand more comfortably. However, the distance between the milker and the cow's udder may also increase because the cow may not choose to stand lined up to the hock rails. Consequently, the cow would be further away from the milker and, as such, negatively affect his or her posture. Tuure and Alasuutari (2009) showed that an increased distance between the cow's udder and the milker caused a poor working posture for the milker. In that case, if the size of milking stalls is increased, cow behavior may affect the health and safety of milking personnel as it becomes more difficult for the milker to reach the udder. In response to this issue, most milking technology companies now offer the option to install indexing milking stalls, where each cow is gently pushed backward, to line up to the hock rail, which enables the use of individual milking parlor dimensions and, accordingly, a better positioning of each cow (Moreau, 1994). When investing in new milking parlors, small farms in particular are often on a limited budget. Consequently, ergonomics are not sufficiently prioritized despite the risk of musculoskeletal disorders of the upper limbs and compromised health (Douphrate et al., 2013).

In the current study, therefore, we evaluated the effect of milking stall dimensions on milkers' upper limb and shoulder muscle activity (as a measure of workload), estimated from surface electromyography (sEMG) during milking. The activity of 8 upper limb and shoulder muscles largely involved in cluster attachment was monitored in 9 professional milkers during milking of the same set of cows in standard and large stalls in a herringbone (HB) and a side-by-side (SBS), which is also known as a parallel, parlor. We expected greater muscle activity in large milking stalls, which would reveal an increased workload for the milker. Studies similar to ours are important to ensure that legislation improving animal welfare does not jeopardize human health.

\section{MATERIALS AND METHODS}

\section{Milking Parlor}

The research was carried out in the experimental milking parlor of Agroscope in Tänikon, Switzerland. This experimental milking parlor could be interchanged between HB (Figure 1) and SBS milking parlors, and milking stall dimensions were adjustable in length, depth (only in HB), and width (Figure 2). We performed ergonomic measurements in the 2 parlor types (HB and $\mathrm{SBS})$. In the $\mathrm{HB} 30^{\circ}$ parlor $(2 \times 5)$ with standard exit, muscle activity of each of the 9 milkers was measured separately during 2 full shifts of evening milking (January and February 2015). In a second step, the parlor was converted to an SBS parlor $(2 \times 5)$ with rapid exit, and similar measurements were recorded for the same 9 milkers over 2 full shifts of evening milking in the SBS parlor (March and April 2015). The milking considered in the experiment took between 30 to $45 \mathrm{~min}$.

Between the 2 milking shifts within each parlor type, stall dimensions were adjusted from standard to large on one side of the parlor and vice versa on the other side (Table 1). Thus, one side of the milking parlor had large milking stall dimensions $[\mathrm{HB}=1.91 \times 1.53 \times$

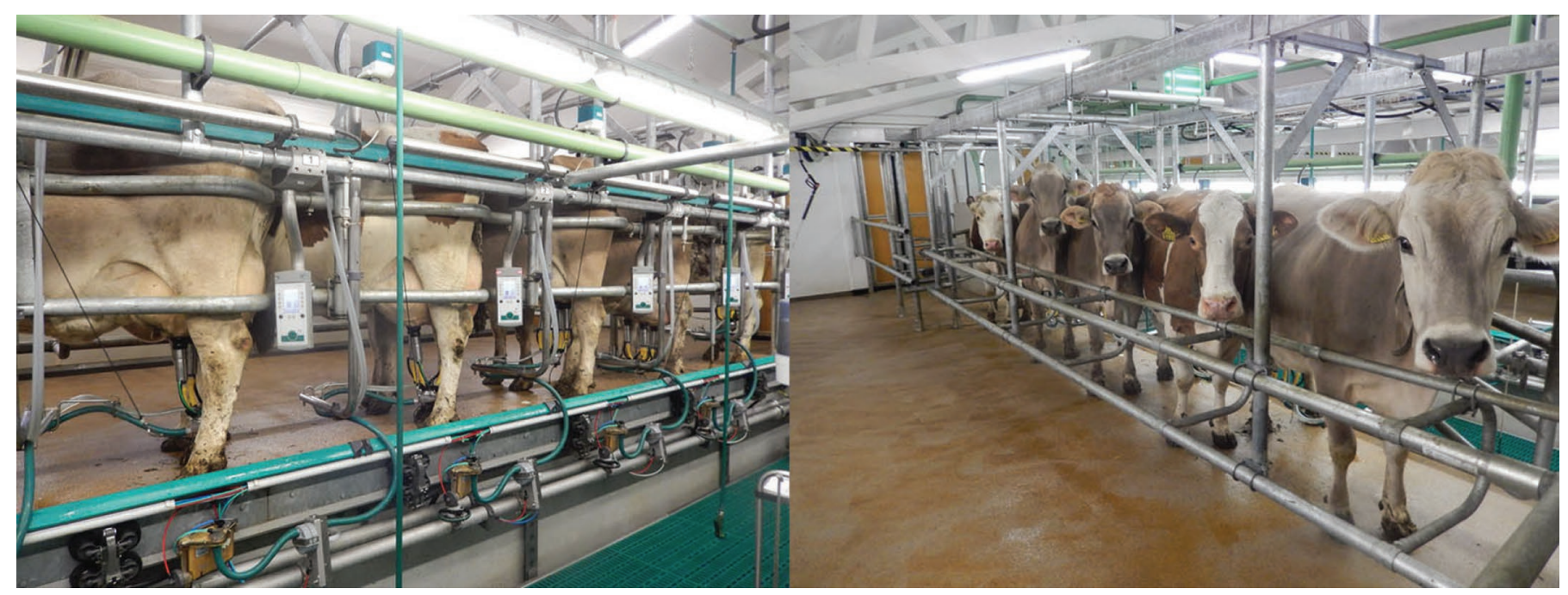

Figure 1. Experimental milking parlor in the herringbone $30^{\circ}$ configuration. 

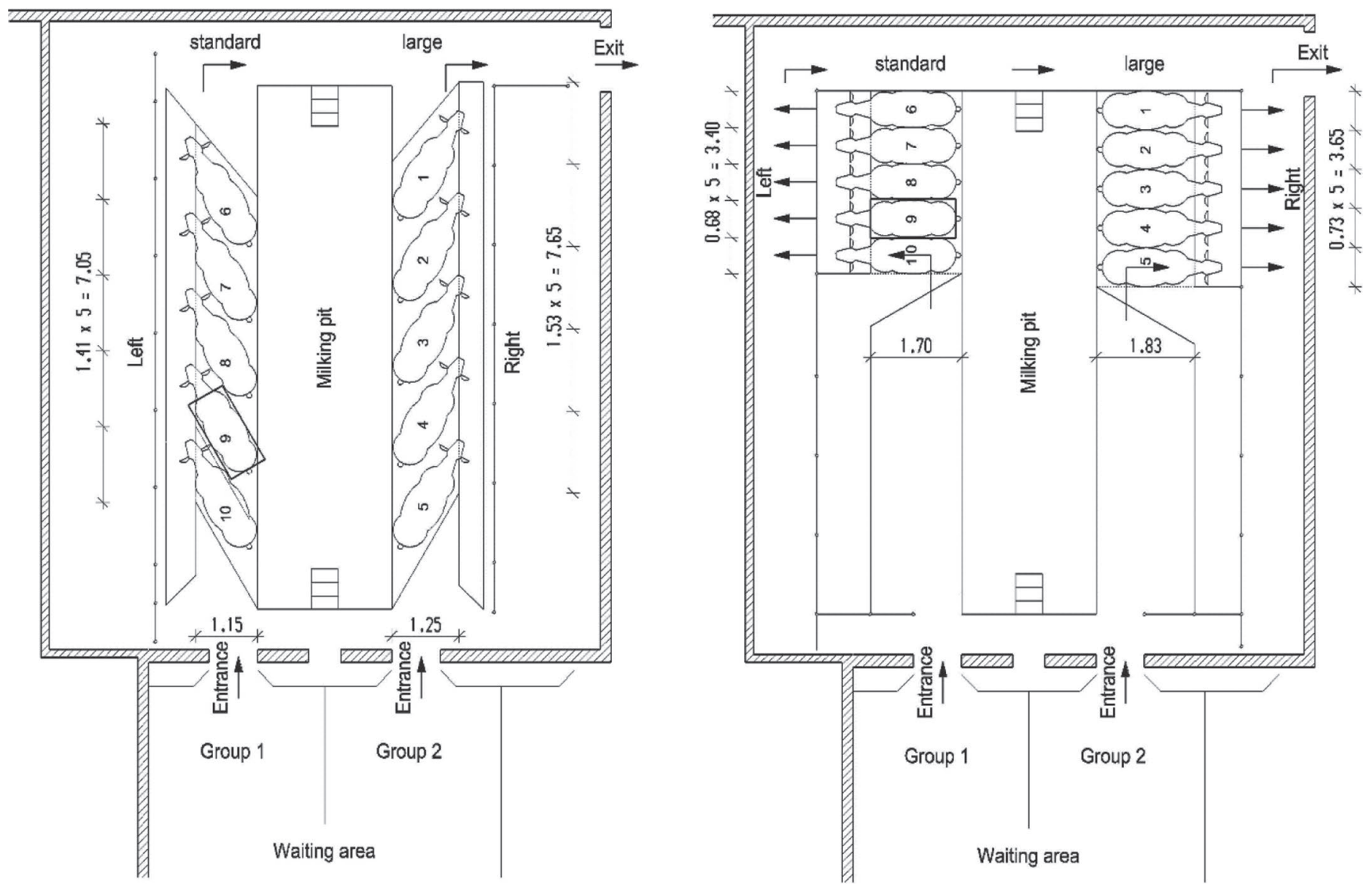

Figure 2. Illustration of the experimental milking parlor. The left image shows the parlor as a herringbone parlor and the right image shows the parlor as a side-by-side parlor. The box shows a milking stall and the numbers indicate the position in the milking parlor. The left side of the parlor shows the standard milking stall dimensions and the right side shows the large milking stalls.

$1.25 \mathrm{~m}$ (length $\times$ depth $\times$ width); SBS $=1.83 \times 0.73$ $\mathrm{m}$ (length $\times$ width)] and the other side had standard stall dimensions $(\mathrm{HB}=1.74 \times 1.41 \times 1.15 \mathrm{~m}$; $\mathrm{SBS}=$ $1.70 \times 0.68 \mathrm{~m}$; Table 1 and Figure 2). The standard dimensions were derived from milking stall measurements on commercial farms (Gómez et al., 2017). The standard HB stalls were $3 \mathrm{~cm}$ longer than the smallest stall found in practice, whereas the standard SBS stalls were $5 \mathrm{~cm}$ longer and $6 \mathrm{~cm}$ wider than stalls found in practice. The chosen stall dimensions differed between 3 and $6 \mathrm{~cm}$ from those found in practice due to the bolt positions that allowed for the adjustment of the milking stalls.

The infrastructure of the experimental milking parlor, including the building and the milking clusters, were similar in both settings; however, the design of the bars and defecation plates differed between the 2 parlor types, with the HB parlor having no manure splash guard. The milking parlor was equipped with an adjustable platform. Milking clusters used were GEA Classic 300 (GEA Farm Technologies GmbH,
Bönen, Germany) and weighed $2.6 \mathrm{~kg}$. The short milk tubes were made of silicone (Siliconform, Türkheim, Germany). Furthermore, the HB parlor was equipped with Posilactors (GEA Farm Technologies GmbH), whereas the SBS parlor was equipped with Posiballs (GEA Farm Technologies GmbH). Posilactors and Posiballs were installed to ensure a correct positioning of the milking cluster during attachment to the cow's udder. The SBS parlor was further equipped with an ergonomic assistance device. When the milker pressed the start button, the milking cluster was let down by a string, which took roughly $3 \mathrm{~s}$ and thus increased the attachment time.

\section{Milkers}

The Swiss Ethics Commission of the Canton of Thurgau approved the experiment (KETGOV2014/25). Nine experienced male milkers took part in the experiment and provided written informed consent to participate in the study. Milker body height ranged between 1.69 and 
Table 1. Details on size dimensions of milking parlors and experimental setting

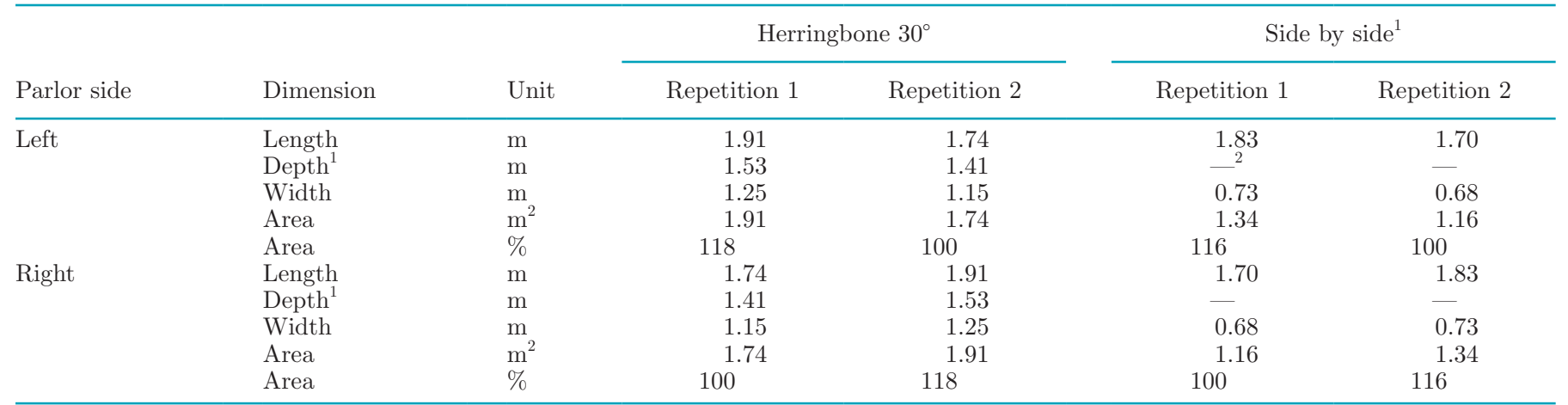

${ }^{1}$ The depth includes the head area in the herringbone parlor $(0.35 \mathrm{~m})$.

${ }^{2}$ Indicates that the dimension is not applicable for the parlor type.

$1.93 \mathrm{~m}($ mean $\pm \mathrm{SD}=1.76 \pm 0.09 \mathrm{~m})$ and mean arm length (measured from the digitus medius to the acromion process) of the right and left arms were $0.79 \pm$ 0.05 and $0.79 \pm 0.04 \mathrm{~m}$, respectively. Eight milkers were right handed and 1 milker was ambidextrous. Milkers were in good health, had a body mass index of below 30 $\mathrm{kg} / \mathrm{m}^{2}$, and participated voluntarily. Each milker was required to milk 30 cows during each of the 4 milking shifts. The floor height was adjusted to suit the body height of each milker. The milking health formula was used to adjust the floor height to a comparable relative level (Cockburn et al., 2015). We used an adjustment coefficient of 0.775 , which was multiplied by the milker's height, for both parlor types. Consequently, the depth of pit (standing surface of the milker to standing surface of the cows) for each milker was calculated as

$$
\text { Depth of pit }=(\text { milker's height } \times \text { coefficient })
$$$$
\text { - (herd-mean udder height). }
$$

\section{Cows}

The Veterinary Office of the Canton of Thurgau approved the experiments (TG 05/2014). Milking was part of the cows' daily routine and the farm staff ensured good animal welfare. The herd, consisting of 52 lactating dairy cows, was housed in 1 loose barn and divided into in 3 groups. Groups 1 and 2 each consisted of 15 healthy dairy cows in lactation. These groups were housed in similar conditions with deep litter bedding. Breeds included crossbred Holstein $\times$ Swiss Fleckvieh and Brown Swiss. The mean udder heights $( \pm \mathrm{SD})$ were $0.56 \mathrm{~m}( \pm 0.06)$ in group 1 and $0.56 \mathrm{~m}( \pm 0.05)$ in group 2 . The 2 groups were herded into separate compartments of the waiting area. Group 1 always entered the milking parlor on the left side, whereas group 2 always entered the parlor on the right side (Figure 2). Thus, the milkers milked each of the 30 cows once with standard milking stalls and once with large milking stalls in both the HB and the SBS parlor (in total, 120 milkings per milker). Group 3 included the remaining cows, was milked after groups 1 and 2, and was not included in the study. Cows' length and width were measured via image analysis of pictures taken from top view using a tall tripod system connected with a remote release device (Gómez et al., 2017); cow size was balanced between groups.

\section{Observations}

An observer documented the initiation of a new attachment procedure, which was indicated by the swinging of an accelerometer when the milker pressed the button to release the milking cluster. The observer further documented the initiation of premilking, udder cleaning, and attaching the milking cluster and noted the cow's position in the milking parlor (Figure 2) and the cow number by using the app Timekeeper (SIA Devitude, Liepāja, Latvia).

\section{Measuring Devices}

The Trigno wireless sEMG system (Delsys, Boston, MA) was used to record mean and maximal muscle activity of milkers during the working routine. Each sensor measured $37 \times 26 \times 15 \mathrm{~mm}$, weighed $14 \mathrm{~g}$, and comprised 2 bar electrodes and 2 reference bar electrodes. Before sensor placement, the skin was prepared by shaving and cleaning with alcohol. In total, 8 sensors were placed on the right and left flexor carpi ulnaris (FC), biceps brachii (BB), deltoideus anterior (DA), and upper trapezius (UT) muscles (Figure 3). All sensors were positioned parallel to muscle fibers, as described by Konrad (2006). These muscles were 
selected due to their role during the attachment of the milking cluster (Cockburn et al., 2015). The cluster is held in the palm of one hand and, as such, requires wrist flexion, which is provided by the FC. The BB is responsible for elbow flexion, which is relevant for lifting and holding the cluster. The DA is in control of shoulder abduction and flexion and plays a vital role when the cluster is moved forward, away from the milker's body underneath the cow's udder. During this movement, the shoulder may also be lifted, which is facilitated by the UT muscles.

Signal quality was checked before data collection using the EMGworks Acquisition software (Delsys); these (sEMG) data were recorded at a sampling frequency of 1,926 Hz. Additionally, 1 Trigno sensor was attached to the observer's hand and preset as an accelerometer with a sampling frequency of $184.1 \mathrm{~Hz}$. As the sEMG and accelerometer data were recorded with the same software, the accelerometer was used to mark the beginning of the attaching procedure in the sEMG data. The initial change before the peak of the acceleration traces (which was the result of the observer marking the starting point) was used as the starting point of the attachment procedure (Figure 4); the endpoint was established where the sEMG activity of the DA decreased to almost zero (Figure 4). When the activity of the DA muscle (shoulder flexion) decreases, the milker would not be able to hold the cluster underneath the cow's udder; hence, it was chosen as an endpoint of the attaching procedure for all muscles.

The experimental procedures were filmed using Mobotix cameras (Mobotix AG, Langmeil, Germany), allowing re-examinations and evaluation of ambiguous occurrences in the sEMG data. The milkers were not instructed to hold the cluster in a specific way, as we wanted to prevent any effects due to a change in their habitual working routine. As a result, some milkers would hold the clusters predominantly in the right hand, some in the left hand, and some would switch hands depending on the parlor side they were milking. The hands used to hold and attach clusters were identified from videos, and it was evident that the attaching procedure strongly varied between milkers. Consequently, the first arm (left or right) that showed a relaxation (decrease in muscular activity) was used to define the endpoint. The time intervals between starting point and endpoint were compared with the time intervals of the attachment procedure on the videos to ensure correct data alignment.

\section{Experimental Procedure}

Before each evening milking, each milker completed 2 maximal voluntary contractions (MVC) in static or isometric conditions (constant muscle length) for each side of the body per monitored muscle (16 MVC in total). An MVC presents a voluntary contraction of a muscle during which the tested subject exerts a maximal effort against a fixed resistance. An MVC is performed to normalize the measurements. The duration of each MVC was 3 to $5 \mathrm{~s}$ (Konrad, 2006) and the resistance was applied manually by the observer. The MVC of the FC was performed by asking the milker to turn the ventral side of the lower arm upwards while the upper arm remained parallel to the trunk. The milker was then asked to flex the wrist upwards with a joint angle of $\sim 120^{\circ}$. The MVC of the BB was performed by asking the milker to perform an elbow flexion from a position of $\sim 90^{\circ}$. The MVC of the DA was performed by asking the milker to lift his lower and upper arm forward against a resistance while the elbow joint re-

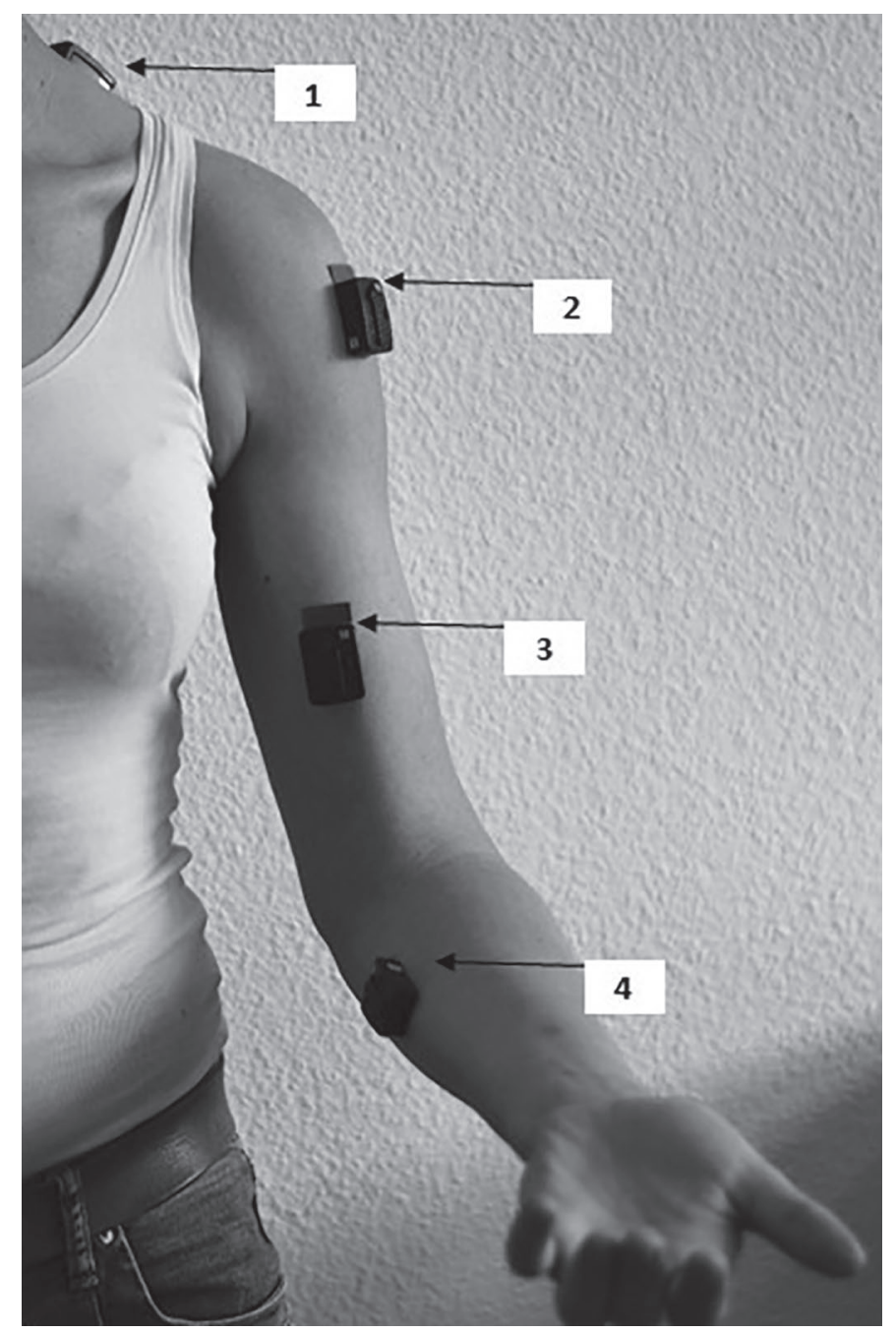

Figure 3. Position of sensor placement: right and left (1) upper trapezius, (2) deltoideus anterior, (3) biceps brachii, and (4) flexor carpi ulnaris. 
mained straight and the ventral side of the elbow and the radial side of the hand were facing upwards; the angle of the shoulder was hereby at $\sim 150^{\circ}$. The MVC of the UT was performed by asking the milker to lift his shoulder upwards while the elbow, shoulder, and wrist joints remained fully extended. If the maximal sEMG signal of the $2 \mathrm{MVC}$ differed by more than $10 \%$, a third MVC was performed. The mean sEMG activity of the 2 highest MVC served as a reference $(100 \%)$ for the experimental data and allowed for a valid comparison between and within milkers. All experimental milkings were conducted during the evening at $1600 \mathrm{~h}$. A farm staff member who was familiar with the milking parlor and the animals was present during all milkings. For each milking, the milkers were required to premilk the cow, clean the udder, press the button to release the milking cluster, and attach the milking cluster; they were asked to milk cows consecutively (1-5 and 6-10; Figure 2).

\section{Data Analysis}

The sEMG and accelerometer data were processed simultaneously with EMGworks Analysis software (Del- sys). Nonphysiological data, which can occur through movement of the sensors (e.g., when sensors are caught on clothing or rails), appear as artifacts (peaks) in the raw sEMG data. Artifacts were defined as any visible shift $<5 \mathrm{~ms}$ with an abnormal amplitude, based on baseline sEMG. Thus, raw data were visually checked for artifacts, and attachment procedures with artifacts were omitted (sEMG sequences with artifacts were not evaluated) from the analyses (percentage of omitted data: $\mathrm{HB}=1.7 \%, \mathrm{SBS}=2.4 \%$ ). Particularly, the right trapezius data were contaminated with the most artifacts in both parlor types (percentage of omitted data: $\mathrm{HB}=5.6 \%$, SBS $=7.8 \%$ ) as well as the left flexor carpi ulnaris in the SBS parlor (percentage of omitted data: $\mathrm{HB}=1.49 \%, \mathrm{SBS}=4.6 \%$ ). The greater numbers of artifacts in the SBS parlor can be explained by sensors being moved by the string that lifts up the milking cluster. As the raw sEMG was measured in millivolts, the root mean square values were calculated with a window length of $0.25 \mathrm{~ms}$ (using one of the functions in the EMGworks Analysis software) by roughly averaging 481.25 sampling points. These values were then used for all additional analyses. The offset of the sEMG signal was also removed, which ensured that all data

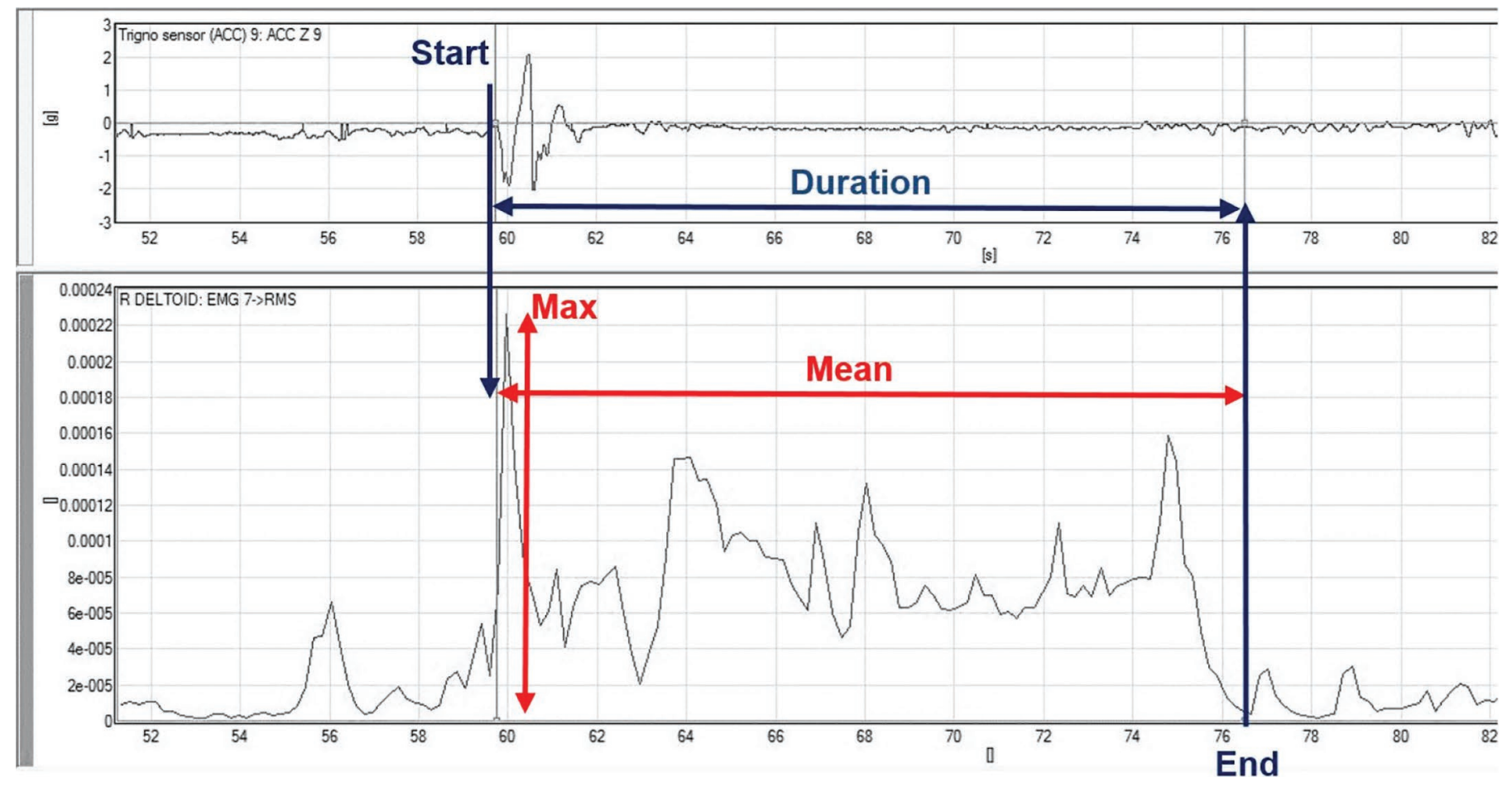

Figure 4. The bottom plot shows the raw surface electromyography (sEMG) measurements for one muscle (right deltoideus anterior). All sEMG measurements were listed on the same time axis, as they were measured through the same software and could therefore be selected and calculated simultaneously. The figure shows how the parameters were calculated. The starting point of the attachment procedure was set at the initial change of the accelerometer's z-axis (top plot). The endpoint was set after the first decrease of muscular activity of the deltoideus anterior to almost zero (bottom plot). The decrease of deltoideus anterior activity was chosen as an endpoint of the attaching procedure for all muscles. Subsequently, the sEMG values were normalized to the subject's maximum voluntary contraction (\% MVC). 
of relaxed muscles originated from zero. No additional filters were used.

Acceleration data were recorded on 3 axes (x, y, and $\mathrm{z}$ ), but only the z-axis (vertical) was retained. The mean and maximum muscle activity during the attachment procedure and the duration of each attachment procedure were calculated with the software package EMGworks (Figure 4); this data set was then transferred to an Excel spreadsheet (Microsoft Office 2013, Redmond, WA). Data were lined up with the additional information on cow number, cow position in the milking parlor, and repetition (1-15). Finally, R version 3.1.0 (R Core Team, 2013) was used to normalize the sEMG data of each milker, muscle, side, and condition to respective MVC data by calculating the percentage of the milker's mean MVC amplitude values (\% MVC).

\section{Statistics}

Statistical analysis was performed separately for the mean, maximum, and duration values in the $\mathrm{HB}$ and SBS milking parlors and for each muscle on each side in $\mathrm{R}$ version 3.1.0, resulting in 34 models. The statistical analysis was performed separately for the HB and the SBS parlor. A linear mixed-effects model was fitted in which mean and maximal normalized muscular activity and duration were used as the target variables. Milking stall dimension (factor with 2 levels: standard, large), cow body length (continuous), milker height (continuous), udder height (continuous), and all their potential interactions, as well as repetition (continuous), were used as fixed effects. The model included the parlor side nested in milker and nested in measuring period, as well as the milker identity and the cow identity as crossed random effects.

The model was fitted using the lmer function in $\mathrm{R}$ (package $=$ lme4; Bates et al., 2015). After fitting of the model, the residuals were checked graphically for normal distribution and homogeneity of variance. To satisfy these assumptions, all normalized values of muscle activity (\% MVC/100) and durations were logit or log-transformed, respectively. In a few cases, it was necessary to remove outliers to ensure normally distributed residuals (numbers of outliers removed per target variable were between 0 and 4 ).

The dredge function (package $=$ MuMIn) was used to find the best model based on the smallest Bayesian information criterion and largest model weight (Bartoń, 2013). The model weight can be interpreted as the probability for a specific model to be optimal in the set of considered models given the data, where the largest model weight of all models in a set add up to 1 (Symonds and Moussalli, 2011). Here, our set included the maximum model as described above and all simpler models including the null model, with an intercept only, a so-called all-subset approach. Two models with a difference in Bayesian information criterion of less than 2 can be considered equivalent (Raftery, 1995; Symonds and Moussalli, 2011), and the simpler model of 2 such models was chosen during model selection when models had similar probability as advised for the Akaike information criterion (Richards et al., 2011). The evidence ratio reflects how many times the chosen model was more likely compared with the null model (Symonds and Moussalli, 2011). This approach in choosing a model is an alternative to frequentist $P$-value based testing and, therefore, no $P$-values are presented.

\section{RESULTS}

Milking stall dimensions were included in the best model in 5 out of 17 models for the HB milking parlor and in 1 of the 17 models for the SBS milking parlor (Table 2). The null model was the best model in most cases (Table 2). Model estimates and confidence intervals for the mean and maximum muscle activities are presented in Table 3. Large milking stall dimensions did not consistently increase muscular activity.

In the HB parlor, we found divergent effects in the left and right $\mathrm{BB}$. Although muscle activity of the left $\mathrm{BB}$ was higher when cows were milked in the large milking stalls, it was also higher in the right $\mathrm{FC}$ and $\mathrm{BB}$ when cows were milked in standard milking stalls. No such effect was found in the left FC (Figure 5; Tables 2 and 3). Furthermore, muscular activity increased over time (with repetition) in the left $\mathrm{BB}$ when cows were milked in the large but not in the standard milking stalls.

In the SBS parlor, we observed no such effects apart from the mean left UT muscle activity, which was higher when cows were milked in standard compared with large milking stalls (Tables 2 and 3). Additionally, mean muscular activity decreased with repetition in the right $\mathrm{BB}$.

In both parlor types, milkers' body height affected muscle activity in all models of the left DA (Figure 6). In the right DA, mean muscle activity increased with repetition in the HB parlor, whereas it increased with increasing udder height in the SBS parlor (Figure 7). Thus, we found consistent effects of both milker and udder height across almost all DA models. Here, short milkers showed higher levels of muscular activity than tall milkers (Figure 6). We found no such effect for any of the other muscles.

Effects of repetition on muscular activity were restricted to the few effects described in the preceding 3 paragraphs. In addition, the models showed a decrease for the duration of the attachment procedure with repetition in the SBS parlor (Figure 8). 
Table 2. Fixed effects included in the optimal model for the target variables, the model weight $\left(\mathrm{w}_{\mathrm{i}}\right)$ based on the Bayesian information criterion, and the evidence ratio in relation to the null model $\left(\mathrm{ER}_{0}\right)$

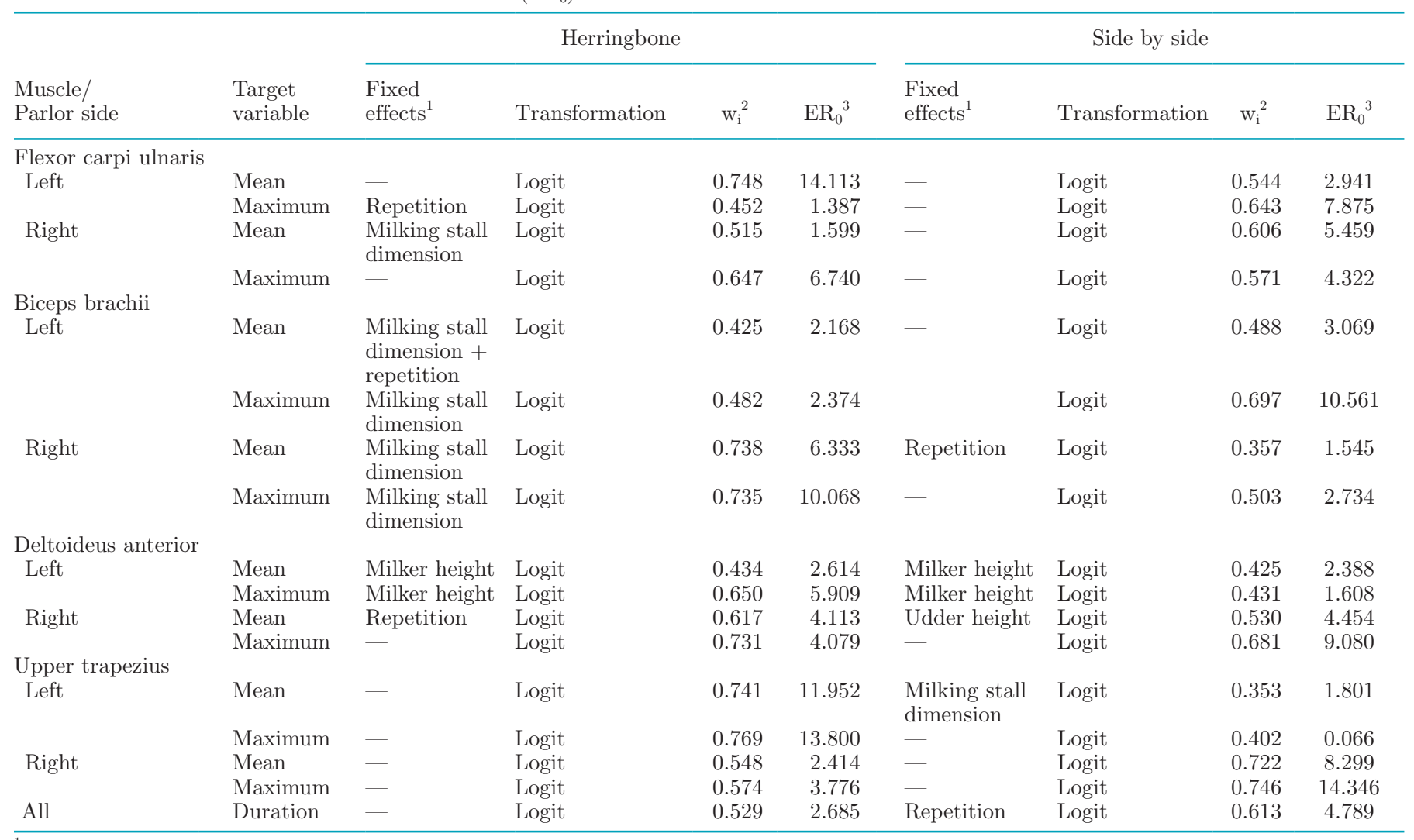

${ }^{1}$ Indicates that the null model was the best model.

${ }^{2}$ The model weight $\left(\mathrm{w}_{\mathrm{i}}\right)$ describes the probability that the chosen model is the best model within the set of models (all-subset evaluation).

${ }^{3}$ The evidence ratio to the null model $\left(\mathrm{ER}_{0}\right)$ describes how many times more likely the model is compared with the null model (with an intercept only).

\section{DISCUSSION}

We did not find consistent effects of milking stall dimensions on muscle activity in milkers because FC and $\mathrm{BB}$ muscle activities were affected in contrasting ways. Therefore, we cannot propose direct recommendations regarding ergonomics for milkers. However, the same methods were applied in a previous study that found benefits of lower working heights (Cockburn et al., 2017). Therefore, we concluded that appropriate working heights are more important than milking stall dimensions for maintaining an optimal posture. For commercial farms, we suggest adjusting space allowance according to increasing cow body size to ensure high comfort for cows without compromising the milkers' health. In the current study, we evaluated 2 extremes, namely standard and large stalls, to increase chances of discovering an effect. In practice, stalls would not need to be as big as the ones used in the large setting of our study, particularly because large stalls bear potential challenges not taken into account in our quantitative sEMG measurements (Cockburn, 2017).

\section{Effect of Milking Stall Dimensions}

Examining the milking process in standard and large milking stalls during our trial, we found that both stall dimensions have specific issues. Body sizes differed between the dairy cows, and thus caused complications during milking. Whereas a few of the large cows did not fit into the standard milking stalls and had to be removed from the study group before the trial, a few of the small cows caused problems when they were milked in the large milking stalls. Here, the milkers had to stretch their upper body underneath the hock rail to clean the udder or attach the milking cluster. This should be considered when evaluating workplace safety, because the hock rail is designed to prevent the milker from being kicked and cannot fulfill its purpose when the milker stretches underneath it. Furthermore, this observation can partly explain why we found no consistent effects on muscle activity. Although we did not measure the distance between cow and milker, cow size was included in the statistical model and showed no effect in any of the monitored muscles. However, 


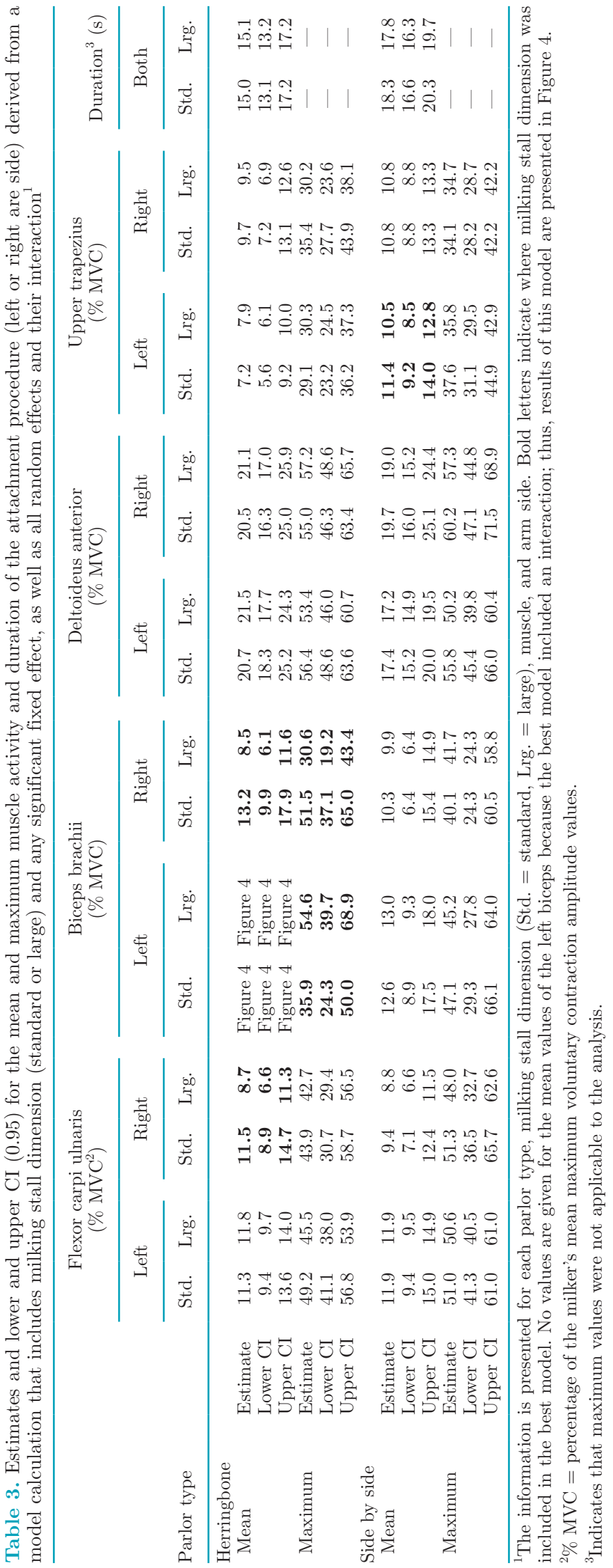

not all cows were too small for the large stalls, and a few of the small cows stepped back within the milking stall, lining up with the hock rail, thus reducing the horizontal reaching distance between milker and cow.

\section{Comparison with Previous Studies}

Jakob et al. (2012) investigated the milking routine with 6 female milking parlor operators and reported that their mean muscular activity ranged between 10 and 15\% MVC during milking cluster attachment. Douphrate and Rosecrance (2010) used electromyography to evaluate the performance of milking tasks in the forearm flexors and extensors, as well as the DA and UT muscles, and found mean peak activation levels of $58 \% \mathrm{MVC}$ in the forearm flexors and $49 \% \mathrm{MVC}$ in the DA; these levels agree with our current findings (Table 3 ). To prevent injury, researchers recommended maximum activation levels of $<50 \% \mathrm{MVC}$, whereas mean activation levels should not exceed $10 \%$ MVC and must not exceed 14\% MVC (Jonsson, 1978, 1982). Adhering to these recommendations could therefore help prevent musculoskeletal disorders commonly reported for milkers, such as carpal tunnel and pronator syndromes (Stål et al., 1998; Patil et al., 2012) and disorders of the shoulders, neck, and wrists (Thinius and Jakob, 2014). We found that muscle activation occurred especially at the beginning of the attachment procedure when the cluster was initially lifted and turned over. Thus, it is worthwhile to consider the possibility of optimizing this part of the milking procedure; for example, by automation or training.

Silvetti et al. (2014) reported DA activity during udder cleaning to range between 21 and 25\% MVC, whereas we found lower mean values of 20 to $21 \%$ MVC in the HB parlor and 17 to $19 \%$ MVC in the SBS parlor during cluster attachment (Table 3). Although the postures were relatively similar, the tasks of cluster attachment and udder cleaning were not fully comparable because the load during udder cleaning was much lower than during cluster attachment. Therefore, we expected our values during cluster attachment to be greater than those measured during udder cleaning. Our finding of a relatively low workload indicates that the cluster weight may have minor effects on the contraction intensity of the DA muscles or that our working heights were better adjusted than those in previous studies.

Douphrate et al. (2017) used sEMG to evaluate the potential of milking cluster design and found that upper trapezius and anterior deltoid activities were highest with heavy clusters (8.2 and $10.3 \% \mathrm{MVC}$, respectively). These values were lower than the upper trapezius activities (7.2-11.4\% MVC) and anterior deltoid activities in the current study (17.2 and 21.5\% MVC). The current 
study, however, reported lower muscle activities for the forearm flexors $(8.7-11.9 \%$ MVC) compared with Douphrate et al. (2017; 17.2-13.8\%MVC). This could be due to the better training of these more frequently milking milkers, a more ergonomic attachment technique, or the fact that the cluster used in our experiment, which weighed $2.6 \mathrm{~kg}$, was heavier than the heaviest cluster tested in Douphrate et al. (2017), which weighed 2.1 $\mathrm{kg}$. However, the DA mean muscle activities observed (17-21\% MVC) in the previous study were the highest among the measured muscles and exceeded the maximum recommended intensities of $14 \%$ MVC (Jonsson, 1978). This finding could explain why many milkers

\section{Left}
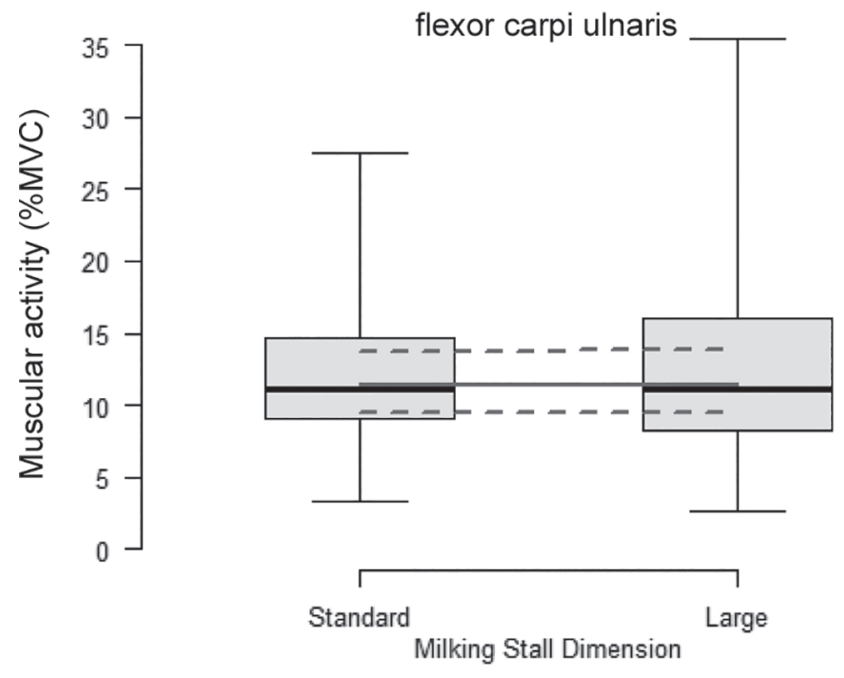

biceps brachii

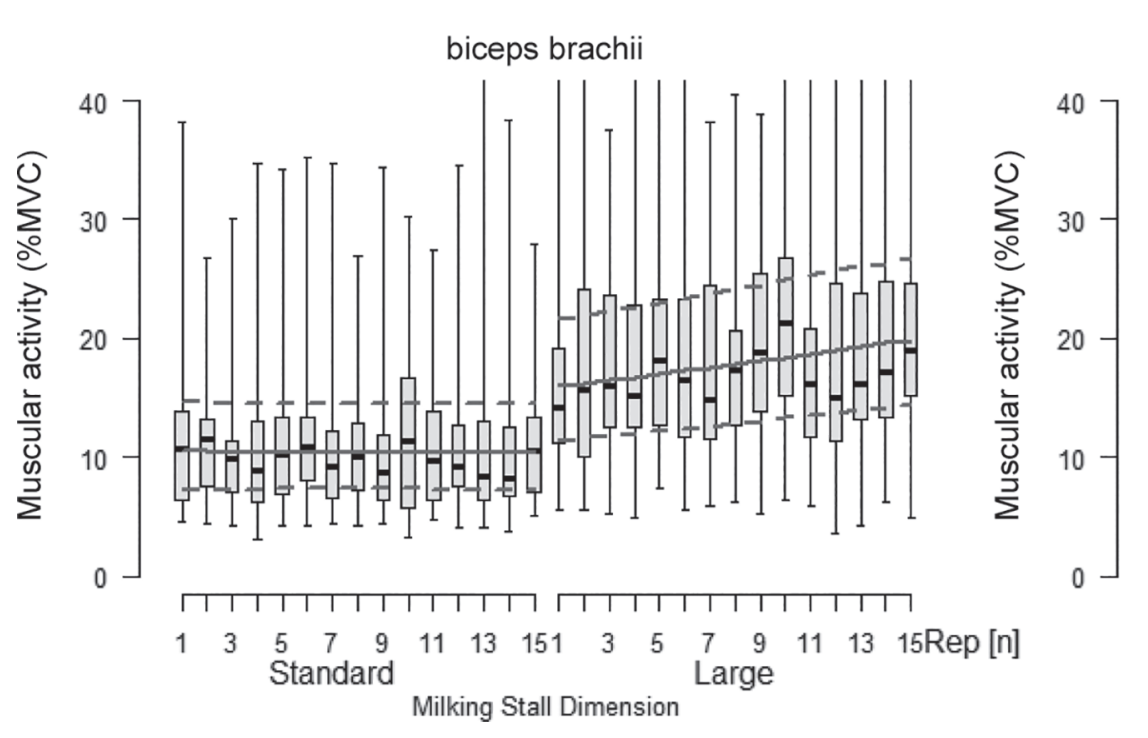

nowadays suffer from shoulder problems (Thinius and Jakob, 2014).

\section{Discussion of Methods}

A potential origin of contrasting findings in the $\mathrm{FC}$ and $\mathrm{BB}$ muscles might have been our measuring procedure. In the current study, we evaluated the main muscles involved in the milking procedure; however, recording synergistic muscle activities between the BB and other muscles, such as the lower back muscles, might have helped explain the contrasting findings. To obtain our data, we followed standard procedures
Right

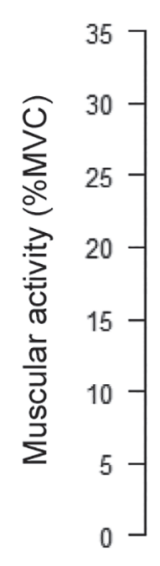

flexor carpi ulnaris

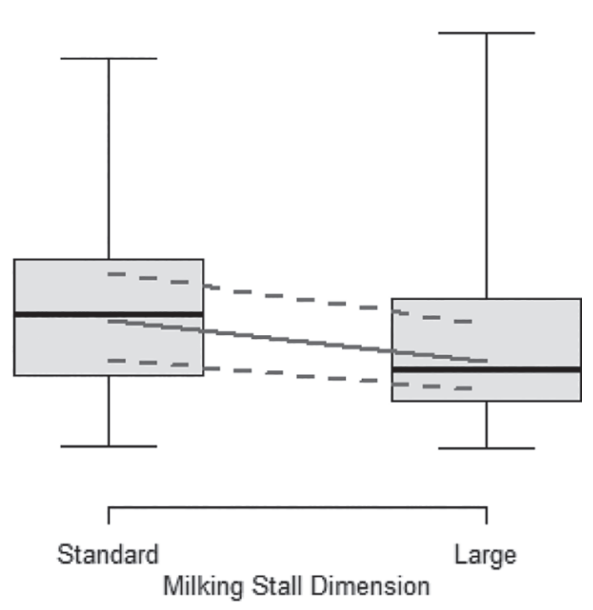

biceps brachii

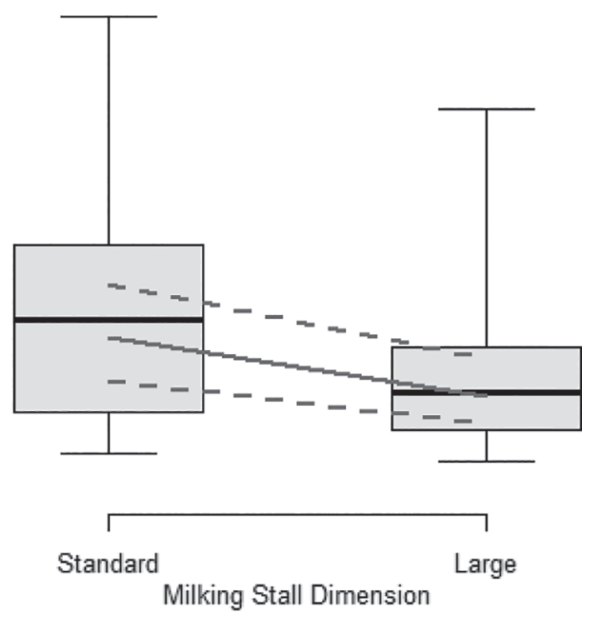

Figure 5. Mean muscular activity of the left and right flexor carpi ulnaris and biceps brachii in the herringbone parlor. Box plots show raw data. The thick black line indicates the median. The upper box indicates the 75 th percentile; the lower box indicates the 25 th percentile. The whiskers show the 95th and 5th percentiles. Lines are model prediction with upper and lower 95\% CI. \% MVC = maximum voluntary contraction. Rep = repetition. 
commonly used to evaluate the working environment of milkers and did not consider the possibility of such synergistic effects (Silvetti et al., 2014; Masci et al., 2016; Cockburn et al., 2017). We point out this issue for 2 reasons. First, we stress that our findings may be compromised by synergetic muscular activity; therefore, recommendations should be considered with caution. Second, researchers would be well advised to consider such effects in the design of future studies. When milking shifted from tethered milking stalls, where milkers sat on a stool, often resulting in knee, hip, and lower back problems, to parlors, such synergetic relationships were not taken into account. Therefore, when milkers started milking in parlors, knee and hip problems were resolved but the discomfort moved to shoulder, elbow, and wrist regions.

\section{Working Height}

Although we did not find consistent effects of stall dimensions, the results show that the individually calculated depth of pit, explained in Cockburn et al. (2017), was largely effective and enabled a comparison between milkers of differing heights. Only the left DA muscle
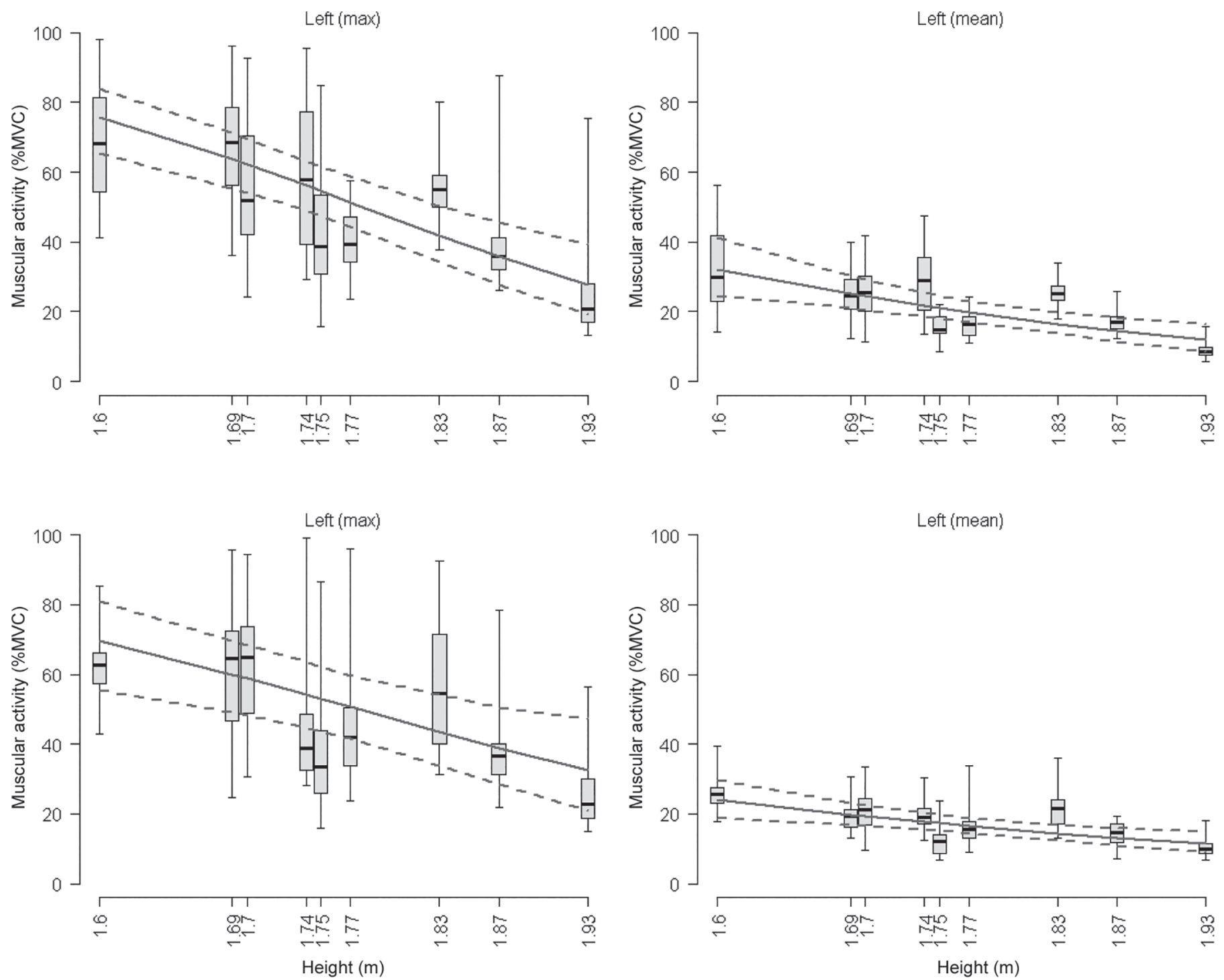

Figure 6. Mean and maximum (max) muscular activity of the left and right deltoideus anterior (DA) during the procedure attaching the milking cluster in both milking parlor types. The top plots show the herringbone data and the bottom plots show the side-by-side data. Box plots show raw data. The thick black line indicates the median. The upper box indicates the 75th percentile; the lower box indicates the 25 th percentile. The whiskers show the 95th and 5th percentiles. The lines between the boxes indicate the model prediction with the upper and lower $95 \%$ CI. $\% \mathrm{MVC}=$ maximum voluntary contraction. 


\section{Herringbone}

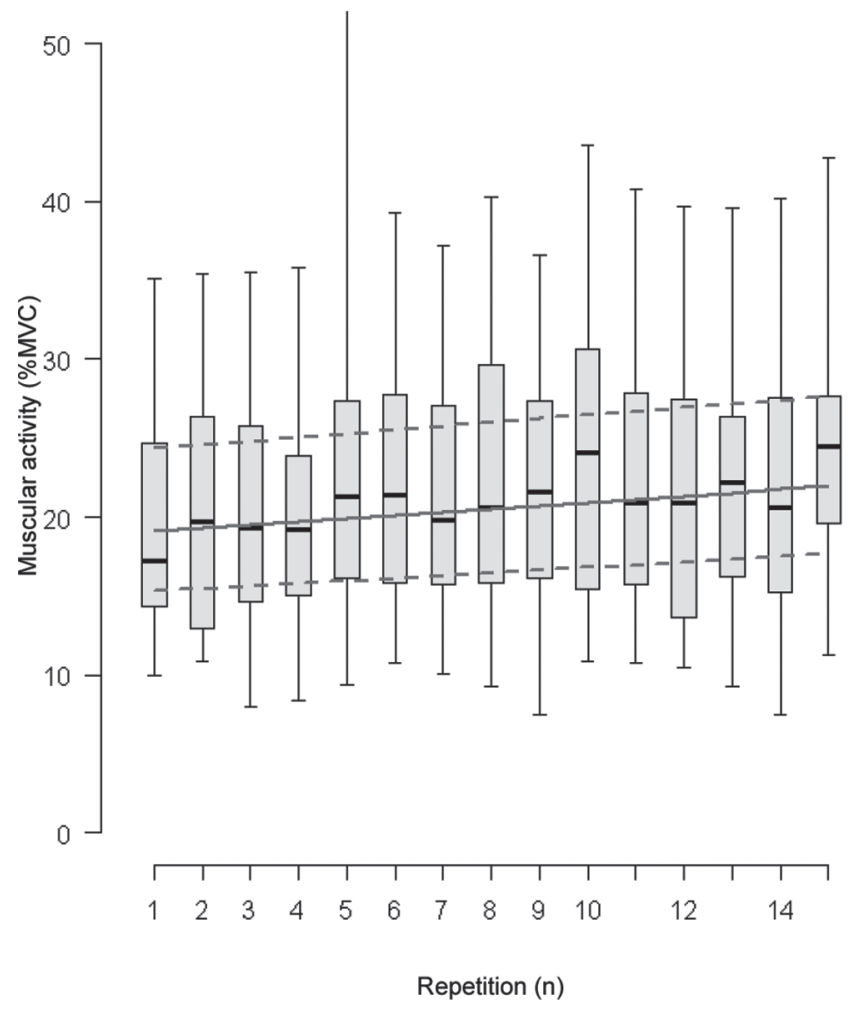

Side by Side

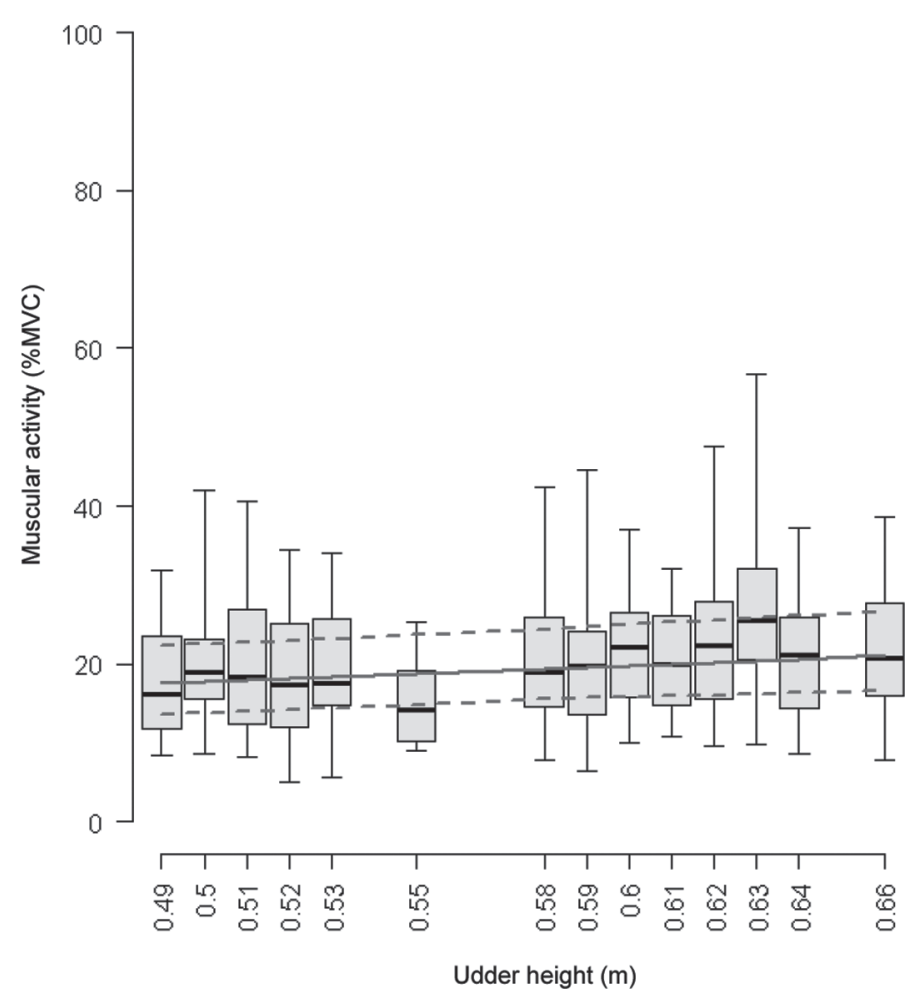

Figure 7. Mean muscular activity of the right deltoideus anterior during milking cluster attachment in the herringbone and side-by-side parlors. Box plots show raw data. The thick black line indicates the median. The upper box indicates the 75 th percentile; the lower box indicates the 25th percentile. The whiskers show the 95th and 5th percentiles. The lines between the boxes indicate the model prediction with the upper and lower $95 \% \mathrm{CI}$. \% MVC = maximum voluntary contraction.

activity was higher in short milkers than in tall milkers. As an observation, short milkers generally observed the udder while cleaning and attaching the clusters, contrary to tall milkers; therefore, the latter milked with a better posture, which is reflected by lower muscle activity of the left DA. Although working heights were the same during the experiment, short milkers were habituated to viewing the udder while attaching the cluster and thus carried on doing this, whereas tall milkers were used to attach the cluster without looking. The left DA is responsible for the forward and upward lifting of the arm, thus this muscle was likely influenced by the horizontal reaching distance. Although not directly considered in the setup of the current study, the horizontal reaching distance was indirectly included in the statistical model as cow body length, which showed no effect. Udder height, however, affected the mean activity of the right DA in the SBS parlor. This effect could be due to the right arm being mostly used to attach the teat cups, which resulted in a greater requirement of vertical lifting with increasing udder height in the SBS parlor.

\section{Fatigue}

An increase in sEMG amplitude over time indicates fatigue (Cifrek et al., 2009). In the HB parlor, maximum muscle activity of the left FC and of several other muscles decreased with increasing repetition number. In the current study, this effect may indicate that milkers were accustomed to their environment and worked more efficiently toward the end of milking. In the right DA, the mean muscle activity increased with repetition, indicating fatigue. However, more interestingly, in the HB parlor, muscular activity of the left BB increased with increasing repetition in the large milking stalls but not in the standard milking stalls. This finding indicates that the large milking stalls, where muscle activity increased, led to a higher muscle recruitment rate to compensate for fatigue occurrence.

\section{Duration of Cluster Attachment}

Milking is highly repetitive work (Pinzke et al., 2001). In a commercial setting, milkers can be required 
Side by Side

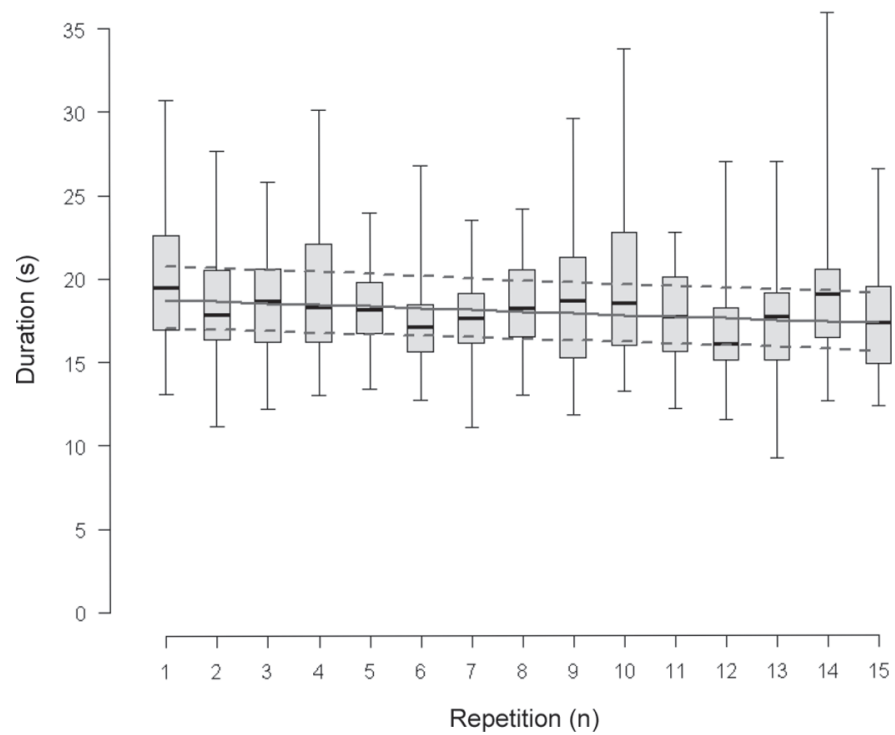

Figure 8. Duration of the procedure attaching the milking cluster in the side-by-side milking parlor. The box plot shows raw data. The thick black line indicates the median. The upper box indicates the 75th percentile; the lower box indicates the 25 th percentile. The whiskers show the 95th and 5th percentiles. The lines between the boxes indicate the model prediction with the upper and lower 95\% CI.

to milk numerous cows and perform the attachment procedure for multiple hours. Thus, the conclusions we can draw from the current study with a relatively small number of repetitions and a total experimental milking time of roughly 30 to 45 min may not be applicable to large farms. Masci et al. (2016) reported that muscular activation levels were higher in milkers working in large-herd US dairies compared with those working in small-herd Italian dairies; however, due to different work procedures, the percentage of work time with muscular rest was also greater in large-herd US dairies.

The current study did not focus on labor evaluation, and the overall mean duration of milking cluster attachment did not differ between milking stall dimensions. However, it decreased with increasing repetition in the SBS parlor. This result could be due to the milker being accustomed to milking in the experimental parlor. The duration of the attachment procedure was, on average, $16 \mathrm{~s}$ in the HB and $18 \mathrm{~s}$ in the SBS parlor. The durations of the attachment procedure in the SBS parlor were considerably longer than the $10 \mathrm{~s}$ per cow reported for an SBS parlor (O'Brien et al., 2007). The longer durations of attachment procedures in the SBS parlor can be explained by the ergonomic assistance available in the parlor. When the milker pressed the start button, the milking cluster was let down by a string, which took roughly $3 \mathrm{~s}$ and thus increased the attachment time.

\section{Milking Techniques}

To ensure routine work and prevent any effect caused by the habituation to a new work routine, all milkers were required to attach the milking clusters in the same way, as they would do on their own farms. The attaching procedures were too variable to systematically evaluate potential differences between the holding and attaching arm. Although most milkers held the milking cluster in one hand and used the other hand to attach each of the teat cups, a few changed the holding side depending on the side of the milking parlor, and a few switched the holding hand during the attachment procedures. However, this behavior was considered in the statistical model, which had a crossover design and included the milker in the random effects, resulting in the evaluation of the differences of milking stall dimensions within each milker; we recommend future research to evaluate various attachment methods and identify the most ergonomic one.

\section{CONCLUSIONS}

Large milking stall dimensions affected but did not consistently increase muscle activity of the measured muscles. Therefore, adjusting milking stall dimensions to current cow sizes does not seem to put the milkers' upper limb and shoulder muscles at an increased risk of developing musculoskeletal disorders. However, the effects on other muscle groups and with regard to fatigue should be further evaluated.

\section{ACKNOWLEDGMENTS}

We thank the Swiss Farm Machinery Association (Bern, Switzerland) for funding this project. Furthermore, we thank all milkers for participating in the study, farm staff for their support throughout the experiments, and Daniel Herzog (Agroscope, Tänikon, Switzerland) for creating Figures 1 and 2.

\section{REFERENCES}

Bartoń, K. 2013. MuMIn: Multi-model inference, R package version 1.9.13. Accessed Feb. 27, 2019. https://cran.r-project.org/package $=\mathrm{MuMIn}$.

Bates, D., M. Maechler, B. Bolker, and S. Walker. 2015. Fitting linear mixed-effects models using lme4. J. Stat. Softw. 67:1-48.

Cifrek, M., V. Medved, S. Tonković, and S. Ostojić. 2009. Surface EMG based muscle fatigue evaluation in biomechanics. Clin. Biomech. (Bristol, Avon) 24:327-340.

Cockburn, M. 2017. Making milking easier-Reducing physical strain of parlor workers during milking cluster attachment. OPUS University of Hohenheim:87. Accessed Feb. 27, 2019. http://opus.uni -hohenheim.de/volltexte/2017/1391/.

Cockburn, M., P. Savary, M. Kauke, M. Schick, U. Hoehne-Huckstadt, I. Hermanns, and R. Ellegast. 2015. Improving ergonomics in milk- 
ing parlors: Empirical findings for optimal working heights in five milking parlor types. J. Dairy Sci. 98:966-974.

Cockburn, M., M. Schick, N. A. Maffiuletti, L. Gygax, P. Savary, and C. Umstatter. 2017. Lower working heights decrease contraction intensity of shoulder muscles in a herringbone 30 degrees milking parlor. J. Dairy Sci. 100:4914-4925.

Douphrate, D. I., C. Lunner Kolstrup, M. Nonnenmann, M. Jakob, and S. Pinzke. 2013. Ergonomics in modern dairy practice: A review of current issues and research needs. J. Agromedicine 18:198-209.

Douphrate, D., and J. Rosecrance. 2010. Industrialization of dairy operations: Ergonomic implications. Pages $16-18$ in Proc. Int. Conf. Work Safety and Risk Prevention in Agro-food and Forest Systems, Ragusa SHWA2010, Ragusa, Italy.

Douphrate, D. I., D. Gimeno Ruiz de Porras, M. W. Nonnenmann, R. Hagevoort, S. J. Reynolds, A. Rodriguez, and N. B. Fethke. 2017. Effects of milking unit design on upper extremity muscle activity during attachment among U.S. large-herd parlor workers. Appl. Ergon. 58:482-490.

Gómez, Y., M. Terranova, M. Zahner, E. Hillmann, and P. Savary. 2017. Effects of milking stall dimensions on behavior of dairy cows during milking in different milking parlor types. J. Dairy Sci. 100:1331-1339.

Hansen, L. B. 2000. Consequences of selection for milk yield from a geneticist's viewpoint. J. Dairy Sci. 83:1145-1150.

Jakob, M., F. Liebers, and S. Behrendt. 2012. The effects of working height and manipulated weights on subjective strain, body posture and muscular activity of milking parlor operatives - Laboratory study. Appl. Ergon. 43:753-761.

Jonsson, B. 1978. Kinesiology: With special reference to electromyographic kinesiology. Electroencephalogr. Clin. Neurophysiol. Suppl. 1978:417-428.

Jonsson, B. 1982. Measurement and evaluation of local muscular strain in the shoulder during constrained work. J. Hum. Ergol. (Tokyo) 11:73-88.

Konrad, P. 2006. The ABC of EMG (version 1.4). Noraxon USA Inc., Scottsdale, AZ.

Masci, F., A. Mixco, C. A. Brents, L. Murgia, C. Colosio, and J. Rosecrance. 2016. Comparison of upper limb muscle activity among workers in large-herd U.S. and small-herd italian dairies. Front. Public Health 4:141.
Moreau, J. R. 1994. Self-indexing exit gate for milking parlor. Google Patents. Norbco Inc., Westmoreland, NY.

O'Brien, B., D. Gleeson, K. O'Donovan, D. Ruane, J. Kinsella, J. Mee, L. Boyle, and J. McNamara. 2007. Labour Efficiency On-Farm. Teagasc, Oak Park, Carlow, Ireland.

Patil, A., J. Rosecrance, D. Douphrate, and D. Gilkey. 2012. Prevalence of carpal tunnel syndrome among dairy workers. Am. J. Ind. Med. 55:127-135.

Pinzke, S., M. Stal, and G.-A. Hansson. 2001. Physical workload on upper extremities in various operations during machine milking. Ann. Agric. Environ. Med. 8:63-70.

R Core Team. 2013. R: A language and environment for statistical computing. R Foundation for Statistical Computing, Vienna, Austria. http://www.R-project.org/.

Raftery, A. E. 1995. Bayesian model selection in social research. Sociol. Methodol. 25:111-164.

Richards, S. A., M. J. Whittingham, and P. A. Stephens. 2011. Model selection and model averaging in behavioural ecology: The utility of the IT-AIC framework. Behav. Ecol. Sociobiol. 65:77-89.

Schönmuth, G., and M. Löber. 2006. Beziehungen zwischen Körpergrösse und Leistungen beim Rind. Zuchtungskunde 78:324-335.

Silvetti, A., M. Gismondi, S. Mari, F. Forzano, A. Ranavolo, and F. Draicchio. 2014. sEMG studies of milking activities in two different working conditions. Pages 5343-5349 in Proc. 5th Int. Conf. Applied Human Factors and Ergonomics. AHFE International, Krakow, Poland.

Stål, M., C.-G. Hagert, and U. Moritz. 1998. Upper extremity nerve involvement in Swedish female machine milkers. Am. J. Ind. Med. $33: 551-559$.

Symonds, M. R., and A. Moussalli. 2011. A brief guide to model selection, multimodel inference and model averaging in behavioural ecology using Akaike's information criterion. Behav. Ecol. Sociobiol. $65: 13-21$.

Thinius, M., and M. Jakob. 2014. Ergonomic workplace evaluation and epidemiology of musculoskeletal discomfort on German dairy farms. Work 49:25-32.

Tuure, V.-M., and S. Alasuutari. 2009. Reducing work load in neckshoulder region in parlor milking. Bornimer Agrartechnische Berichte $66: 48-54$ 